\title{
High Isolation and Ideal Correlation Using Spatial Diversity in a Compact MIMO Antenna for Fifth-Generation Applications
}

\author{
Doae El Hadri (D), ${ }^{1}$ Alia Zakriti, ${ }^{1}$ Asmaa Zugari, ${ }^{2}$ Mohssine El Ouahabi, ${ }^{1}$ and Jamal El Aoufi ${ }^{3}$ \\ ${ }^{1}$ National School of Applied Sciences, Abdelmalek Essaadi University, Tetuan, Morocco \\ ${ }^{2}$ Faculty of Sciences, Abdelmalek Essaadi University, Tetuan, Morocco \\ ${ }^{3}$ International Academy Mohammed VI of Civil Aviation, Casablanca, Morocco \\ Correspondence should be addressed to Doae El Hadri; doae93@gmail.com
}

Received 28 April 2020; Revised 20 June 2020; Accepted 3 July 2020; Published 24 July 2020

Academic Editor: María Elena de Cos Gómez

Copyright (c) 2020 Doae El Hadri et al. This is an open access article distributed under the Creative Commons Attribution License, which permits unrestricted use, distribution, and reproduction in any medium, provided the original work is properly cited.

This paper presents a compact Multiple Input Multiple Output antenna with high isolation and low envelope correlation (ECC) for fifth-generation applications using spatial diversity technique. The proposed MIMO antenna consists of two single antennas, each having size of $13 \times 12.8 \mathrm{~mm}^{2}$, symmetrically arranged next to each other. The single and MIMO antennas are simulated and analyzed. To verify the simulated results, the prototype antennas were fabricated and measured. A good agreement between measurements and simulations is obtained. The proposed antenna covers the $28 \mathrm{GHz}$ band $(27.5-28.35 \mathrm{GHz})$ allocated by the FCC for $5 \mathrm{G}$ applications. Moreover, the isolation is more than $35 \mathrm{~dB}$ and the ECC is less than 0.0004 at the operating band, which means that the mutual coupling between the two elements is negligible. The MIMO parameters, such as diversity gain (DG), total active reflection coefficient (TARC), realized gain, and efficiency, are also studied. Thus, the results demonstrate that our antenna is suitable for $5 \mathrm{G}$ MIMO applications.

\section{Introduction}

In recent years, fifth generation $(5 \mathrm{G})$ has attracted a lot of attention from researchers. This generation is different from the previous ones: it is not only interested in the world of mobile telephony but also addresses other sectors that have an impact on our daily life, such as energy, health, media, transport, and industry. $5 \mathrm{G}$ is announced as the true enabler of the Industry 4.0, which is considered to be the fourth industrial revolution technology [1]. In addition, 5G will also have an intense impact on the Internet of Things (IoT) and will be its key element by supporting the connection of a huge number of objects to the Internet.

In other words, $5 \mathrm{G}$ has the objective of changing the world by connecting everything to everything. To meet these aims, it is necessary to attain high speed, which is one of the important characteristics of $5 \mathrm{G}$ that have been established by the International Telecommunication Union (ITU). In this context, 3GPP ( ${ }^{\text {rd }}$ Generation Partnership Project) Release 15 introduces $5 \mathrm{G}$ technology to meet the declared ITU-2020 objectives including higher spectral efficiency, greater numbers of users, reduced end-to-end latency, higher device connection densities, prolonged device battery life, thousand-fold system capacity, hundredfold energy efficiency, ultrahigh data rate, and ultrawide radio coverage $[2,3]$.

Hence, the $5 \mathrm{G}$ is intended to deliver superfast communication speeds of up to $10 \mathrm{~Gb} / \mathrm{s}$. However, to meet this growing demand for multigigabit per second, millimeterwave is considered to be the most important technology and is a potential candidate for $5 \mathrm{G}$ mobile communication [4]. Furthermore, higher data rates and capacities require more bandwidth [5].

Furthermore, 5G technology can operate in two categories of frequencies: sub- $6 \mathrm{GHz}$ and high frequencies known as millimeter waves. There are many works in the literature concerning this topic for low frequencies, such as [6-9]. However, we can find plenty of papers for high frequencies [10-22]. In this work, we chose the millimeter waves band, precisely $28 \mathrm{GHz}$, for several reasons. It has huge bandwidth compared to microwave frequencies. 
Opposing to signals in bands below $6 \mathrm{GHz}$, the mm-Wave signal has a shorter wavelength, which offers several benefits, such as the small size of the device (making it possible to group a big number of antennas in a compact ensemble), narrow beam width, and better resolution [23]. Among the challenge in the application of millimeter waves are rain attenuation and atmospheric absorption caused by weather, resulting in propagation losses, but many studies [24, 25] have been carried out and demonstrated that propagation losses at $28 \mathrm{GHz}$ are not significant compared to other frequencies. The Federal Communications Commission (FCC) has announced the spectrum of $27.5-28.35 \mathrm{GHz}$ for $5 \mathrm{G}$, and this band is proposed for mobile use [26].

The interference that can be created by obstacles such as buildings, trees, as well as bad weather, is one of the challenges of 5G. To overcome this, it is essential to use antenna technologies like Multiple Input Multiple Output MIMO [27]. Additionally, the MIMO antenna is used to increase the SNR value, improve channel capacity, enhance data rate, and improve Quality of Service (QOS). To evaluate the performance of a MIMO system, the isolation between antenna elements is regarded as one of the important parameters. There are many techniques for enhancing isolation by using Electromagnetic Band Gap (EBG) structures [28], Metamaterial Polarization Rotator (MPP) Wall [29], neutralizing line $[8,30]$, Defected Ground Structure (DGS) [8, 16], splitring resonators (SRRs) [31], metal strips [18], and selfdecoupled structure [7].

The goal of this paper is to propose a compact MIMO antenna operating at millimeter-wave frequency for fifthgeneration applications. By using the spatial diversity technique, high isolation was obtained. The MIMO antenna operates at $28 \mathrm{GHz}$, and the measured bandwidth covers well the band specified by the FCC for $5 \mathrm{G}$ (27.5 GHz-28.35 GHz). The performance of MIMO antenna such as the isolation between two ports, ECC, diversity gain, and TARC are studied. Moreover, the simulated results are validated by the experimental ones and showed an excellent agreement. The suggested MIMO antenna has the advantages of compact size, high isolation, low envelope correlation coefficient, simple structure, and easy to fabricate. Hence, the proposed antenna is a good candidate for MIMO applications and also suitable for use in $5 \mathrm{G}$ cellular mobile communication.

\section{Antenna Geometry}

To design a MIMO antenna, we will first design a single antenna; then, two elements of this single antenna are placed next to each other to construct the desired MIMO antenna, using the technique of spatial diversity. The proposed MIMO antenna design steps are presented in the following section.

2.1. Single Antenna Configuration. The first step is to design a single element antenna for $28 \mathrm{GHz}$ frequency band using the 3D simulator electromagnetic CST Microwave Studio. The radiating element of the proposed antenna is in the shape of " 5 ," as shown in Figure 1. It is printed on a

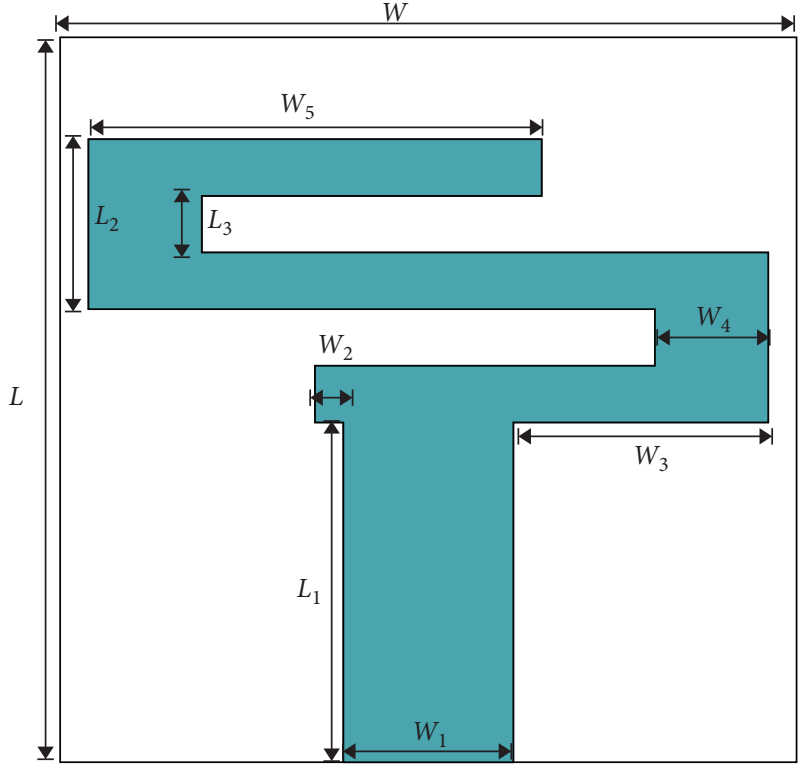

FIGURE 1: Design of the proposed single antenna.

$13 \times 12.8 \mathrm{~mm}^{2}$ FR4 substrate with permittivity of $\varepsilon_{r}=4.4$ and thickness of $h=1.6 \mathrm{~mm}$. In the bottom side of the substrate, a full ground plane is placed. The patch is fed using $50 \Omega$ microstrip line. Table 1 presents the details of the optimized dimensions parameters.

Figure 2 illustrates the evolution stages of the proposed single antenna; and the simulated return loss of three antenna configurations is shown in Figure 3.

The conception starts with a conventional microstrip patch antenna, which provides resonance at $23.3 \mathrm{GHz}$ frequency. In a second step, an $L$-shaped slot is introduced into the radiating element to improve the return loss and shift the resonant frequency to $24.6 \mathrm{GHz}$. In the third step, another L-shaped slot is used to increase the resonance frequency and also to enhance the impedance matching. As can be seen from Figure 3, the corresponding result of the proposed antenna (step (3)) shows that the return loss is more than $30 \mathrm{~dB}$ at $28 \mathrm{GHz}$, which is the desired frequency.

2.2. Two-Elements MIMO Configuration. In a second step, two elements of the single antenna are placed adjacent to each other to form a MIMO antenna that operates at $28 \mathrm{GHz}$, the band licensed for fifth-generation. The two radiating elements are closely spaced with a distance separation of $D=1 \mathrm{~mm}=0.41 \lambda$, with $\lambda$ being free space wavelength at the center frequency. Figure 4 illustrates the configuration of the proposed 5G MIMO antenna.

\section{Decoupling Analysis}

3.1. Mutual Coupling. Spatial diversity is the first kind of isolation improvement technique of MIMO antennas. Then, we will use this technique to ensure the isolation between closely packed antenna elements. In designing MIMO antenna, basically, two types of configurations were being suggested. Figures 5(a) and 5(b) show the asymmetric and 
TABle 1: Dimensions of the proposed antenna parameters.

\begin{tabular}{lcccccccccccc}
\hline Parameters & $L$ & $W$ & WS & $L 1$ & $L 2$ & $L 3$ & $W 1$ & $W 2$ & $W 3$ & $W 4$ & $W 5$ & $D$ \\
\hline Value $(\mathrm{mm})$ & 12.8 & 13 & 26 & 6 & 3 & 1 & 3 & 0.5 & 4.5 & 2 & 8 & 1 \\
\hline
\end{tabular}

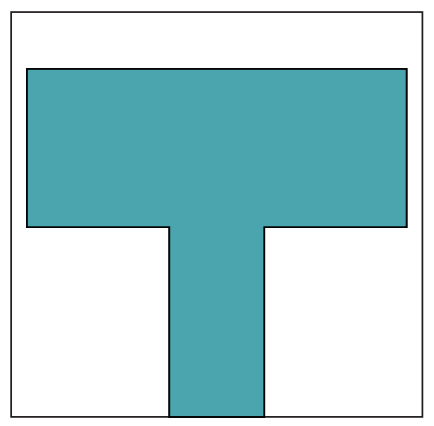

Step (1)

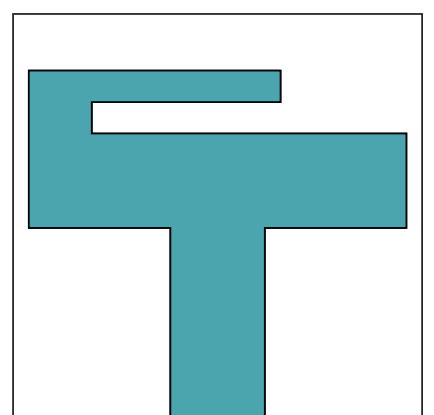

Step (2)

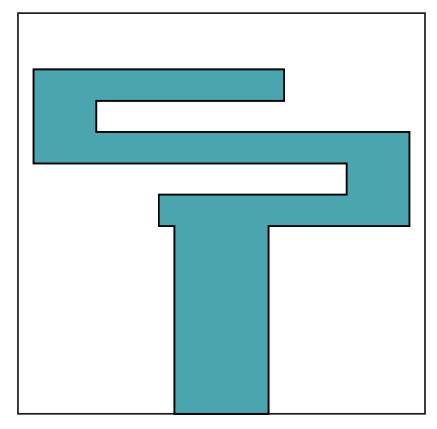

Step (3)

FIGURE 2: Design evolution of the proposed antenna.

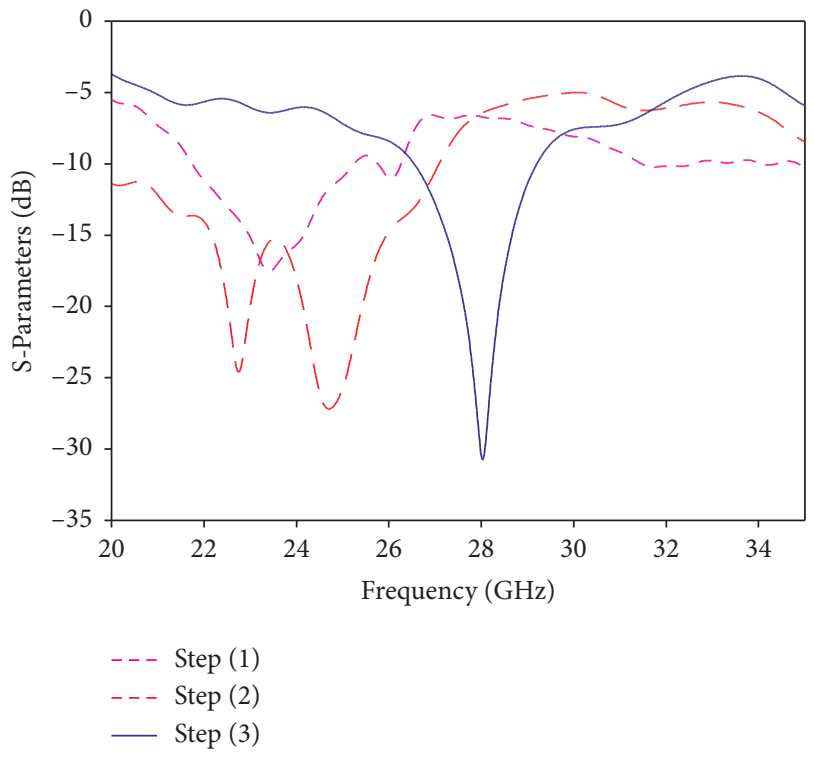

Figure 3: Return loss of three antennas configurations.

symmetric designs of the proposed MIMO antenna, respectively. The simulated S parameters for both configurations are illustrated in Figures 6 and 7.

From Figure 6, it can be seen that the reflection and transmission coefficients are $(S 11=-54.45 \mathrm{~dB}, S 12=-33.37$ $\mathrm{dB}, \quad S 21=-34.19 \mathrm{~dB})$ at $28.115 \mathrm{GHz}$ frequency, while $(S 22=-31.53 \mathrm{~dB}, \quad S 12=-33.09 \mathrm{~dB}, \quad S 21=-33.85 \mathrm{~dB}) \quad$ at $28.085 \mathrm{GHz}$ frequency.

On the other hand, from Figure 7, we can conclude that $S 11=S 22$ and $S 12=S 21$ due to the symmetry. The obtained reflection coefficient is $S 11=S 22=-38.86 \mathrm{~dB}$, and the isolation between port 1 and port 2 is $S 12=S 21=-36.51 \mathrm{~dB}$ at the desired frequency $28 \mathrm{GHz}$. Consequently, there is a lower mutual coupling between the two ports. It is clear that the isolation is better for the second configuration (Figure 5(b)). So, this MIMO antenna configuration has been considered

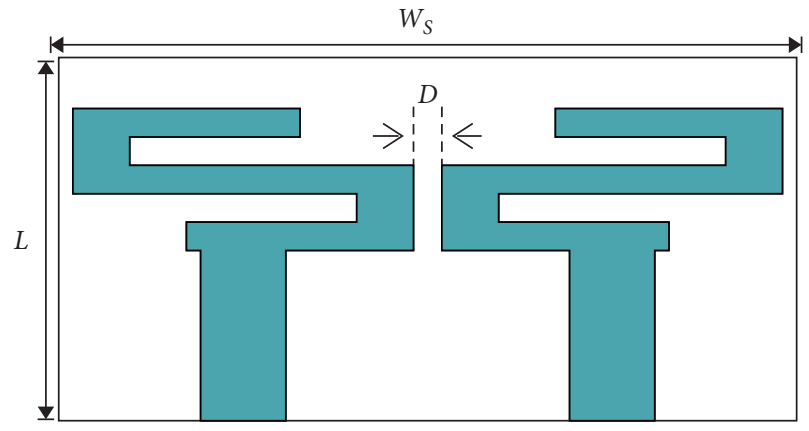

FIgURE 4: Design of the proposed MIMO antenna.

in this work. The spacing constraint must be present to guarantee the compactness of the overall size. The value of the isolation is greater than $35 \mathrm{~dB}$ in this approach for $D=1 \mathrm{~mm}$.

Finally, we can conclude that the isolation was achieved without using any additional decoupling structure while maintaining a minimum spacing of $1 \mathrm{~mm}(0.41 \lambda)$ between the antenna elements.

3.2. Surface Current Distributions. In this section, the distribution of surface currents at the desired $28 \mathrm{GHz}$ mm-wave frequency for the two antenna ports will be studied in order to confirm the decoupling between antenna elements.

Figure 8 represents the simulated surface current distributions when port 1 is excited, and the other port is terminated at $50 \Omega$ and vice versa for port 2. From Figure $8(\mathrm{a})$, it is clear that the current is mainly concentrated around the first element of the MIMO antenna (port 1), while it is focused around the second element of the proposed MIMO antenna (port2), as can be seen in Figure 8(b). Furthermore, the coupling current concentration between the MIMO antennas is negligible. Therefore, it can be concluded that very good isolation between the two antenna elements is ensured. 


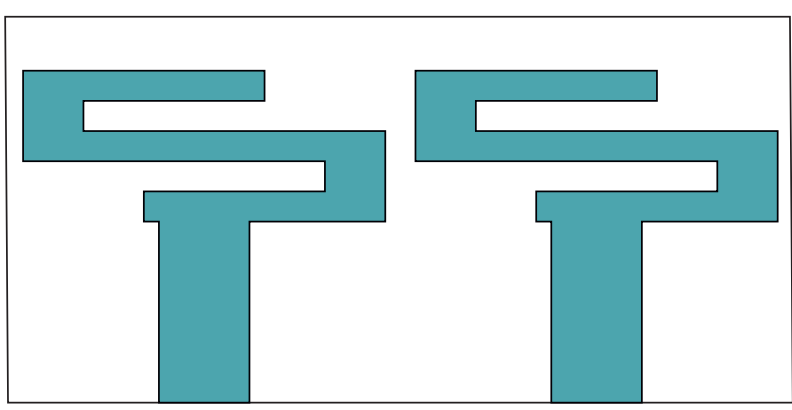

(a)

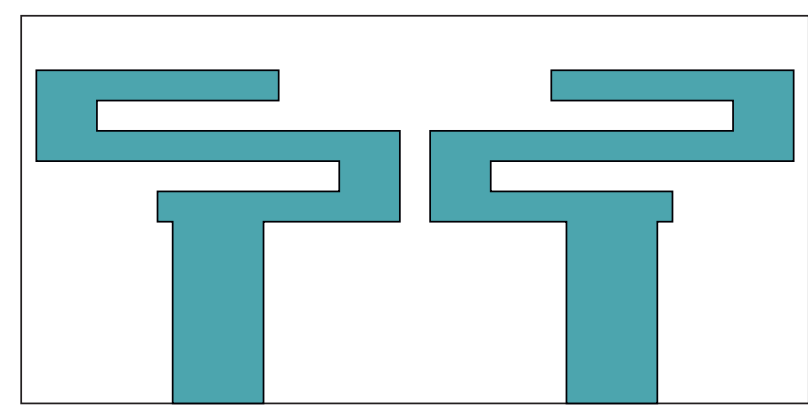

(b)

Figure 5: Antisymmetric (a) and symmetric (b) configuration.

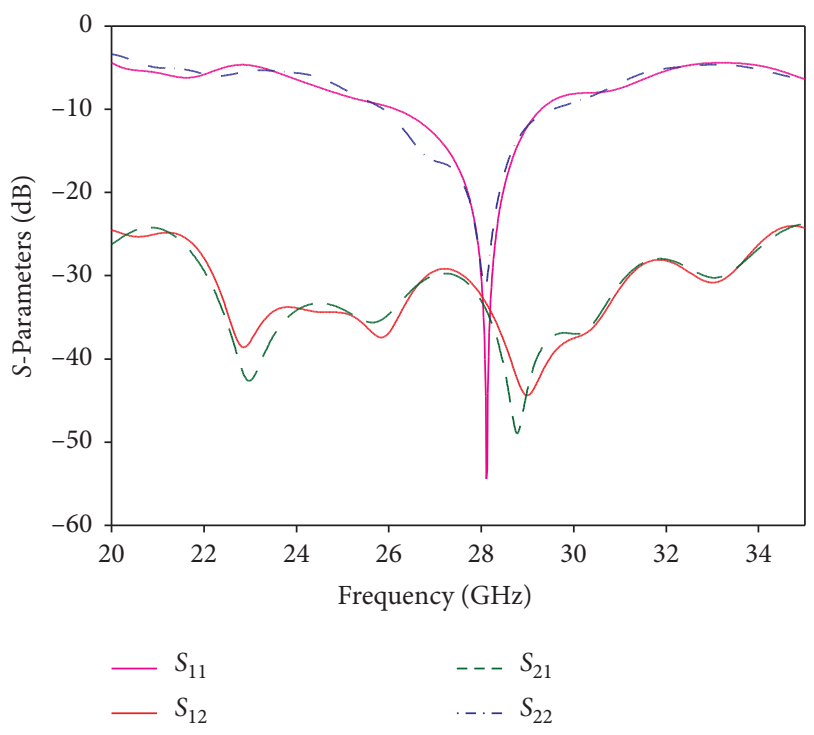

FIGURE 6: S parameters of asymmetric MIMO antenna.

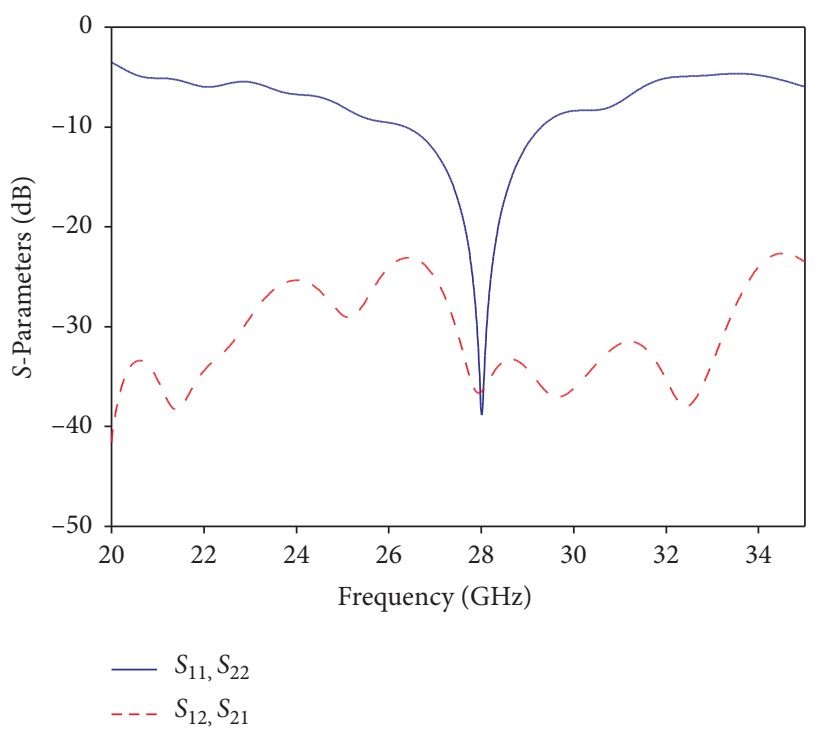

Figure 7: S parameters of symmetric MIMO antenna.

\section{Fabrication, Measurement Results, and Discussion}

4.1. Fabricated Antennas. The process of analyzing an antenna involves three main stages: firstly, the design of the antenna through simulation software; secondly, the manufacturing, and finally, the measurements.

Based on the obtained designs, which are optimized using Computer Simulation Technology (CST) Microwave Studio Software in Section 2, the fabrication of these two antennas (single element antenna and two elements MIMO antenna) is performed using a printed circuit board (PCB) milling machine: the LPKF Proto Mat E33, which is available in our laboratory. Then, the measurement of the $S$ parameters is carried out using the PNA-L Network Analyzer N5234 A (10 $\mathrm{MHz}-43.5 \mathrm{GHz}$ ). The photograph of the fabricated prototype of a single antenna and MIMO antenna is illustrated in Figure 9.

4.2. S Parameters. The measured and simulated reflection coefficient curves of the single $5 \mathrm{G}$ antenna are shown in Figure 10. An excellent agreement can be observed between simulation and measurement results.

As illustrated in Figure 10, the measured and simulated $-10 \mathrm{~dB}$ impedance bandwidths are $(27.36-29.39 \mathrm{GHz})$ and $(26.56-29.3 \mathrm{GHz})$, respectively. Moreover, at the resonant frequency, the simulated reflection coefficient $\mathrm{S} 11$ is $-30.73 \mathrm{~dB}$, while the measured one is $-20.58 \mathrm{~dB}$, which signifies a good adaptation. To make this comparison more clear, Table 2 summarizes the results of the proposed single antenna for the fifth generation.

Because of the symmetric structures of the proposed antenna (i.e., $|S 11|=|S 22|$ and $|S 12|=|S 21|$ ), only the measurement of $S 11$ and $S 12$ was carried out.

Figure 11 shows the measured and simulated reflection coefficient of the proposed MIMO antenna, corresponding to $-37.17 \mathrm{~dB}$ and $-38.93 \mathrm{~dB}$, respectively, at the $28 \mathrm{GHz}$ millimeter-wave frequency band.

The measured and simulated transmission coefficients curves are shown in Figure 12. An acceptable agreement appears for both measured and simulated isolation between the two antenna elements. The isolation is very high; its value 

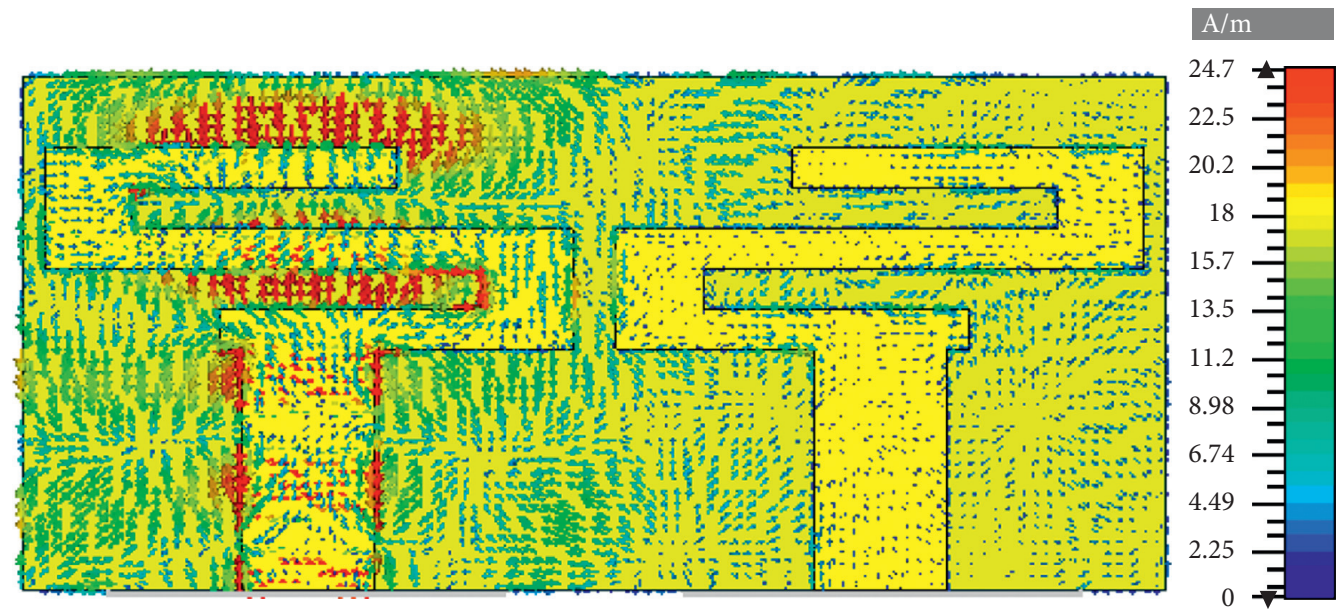

(a)
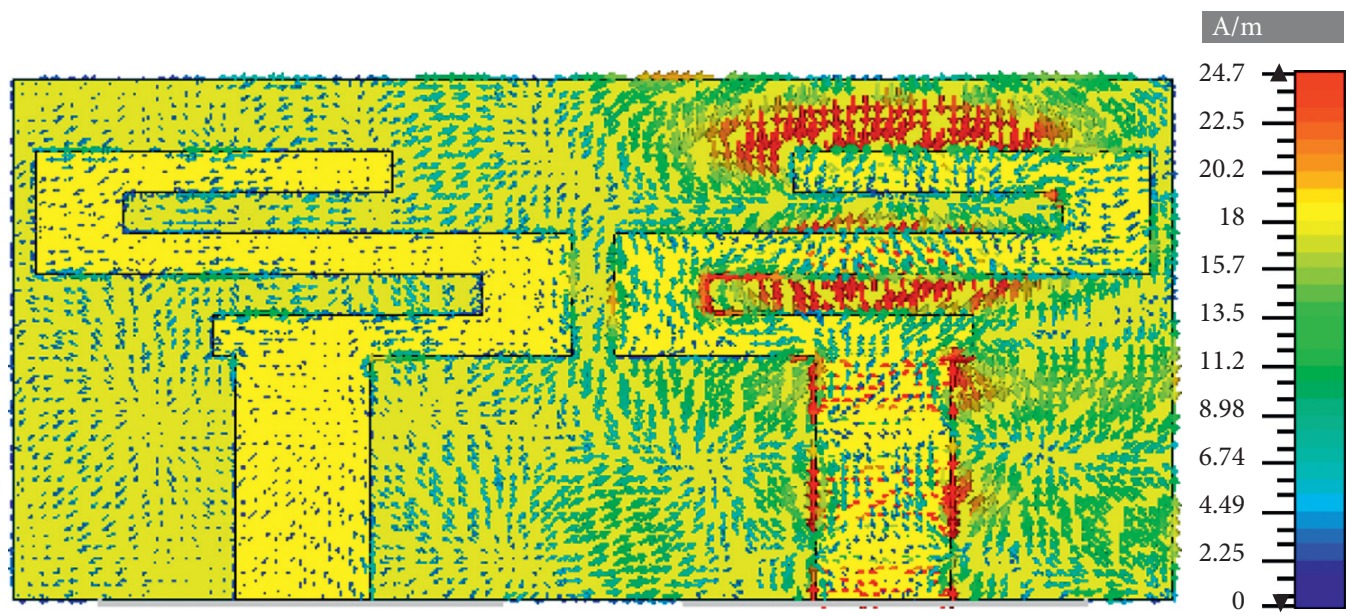

(b)

FIgURE 8: Surface currents distributions of (a) port 1 and (b) port 2 at $28 \mathrm{GHz}$.

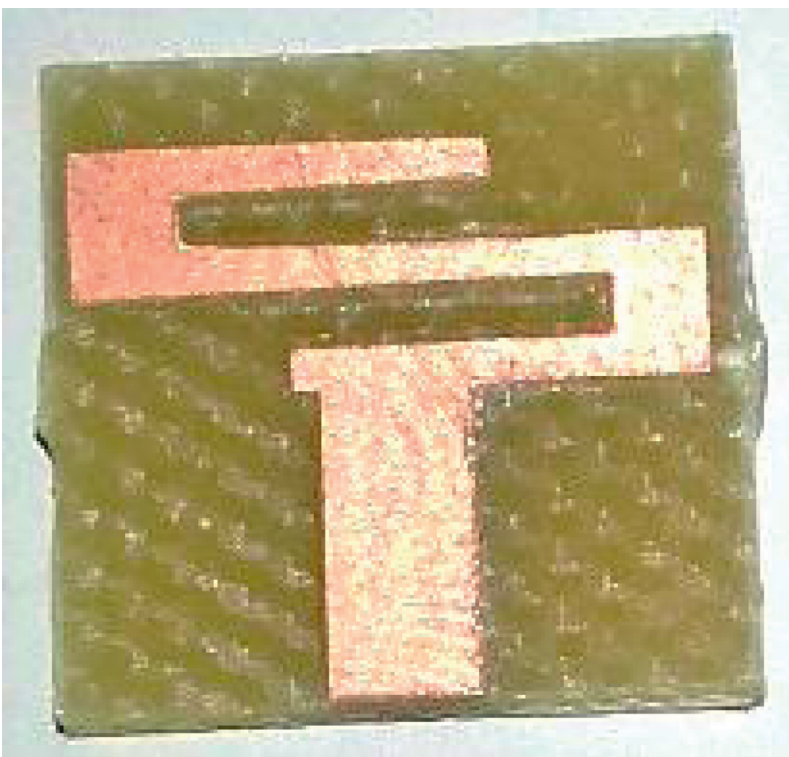

(a)

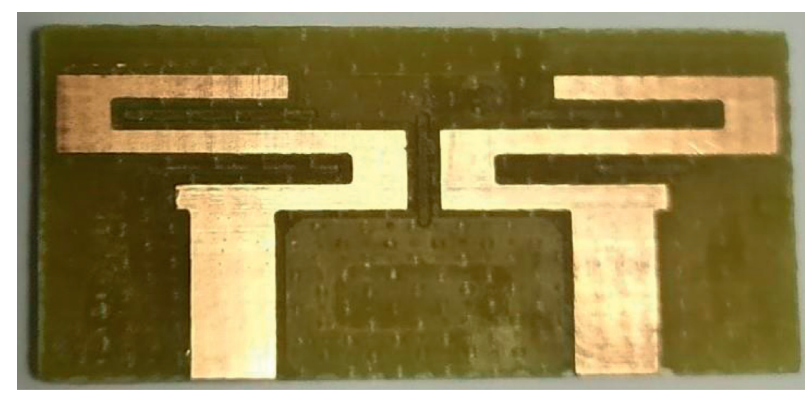

(b)

Figure 9: Photograph of the prototypes: (a) single antenna and (b) MIMO antenna. 


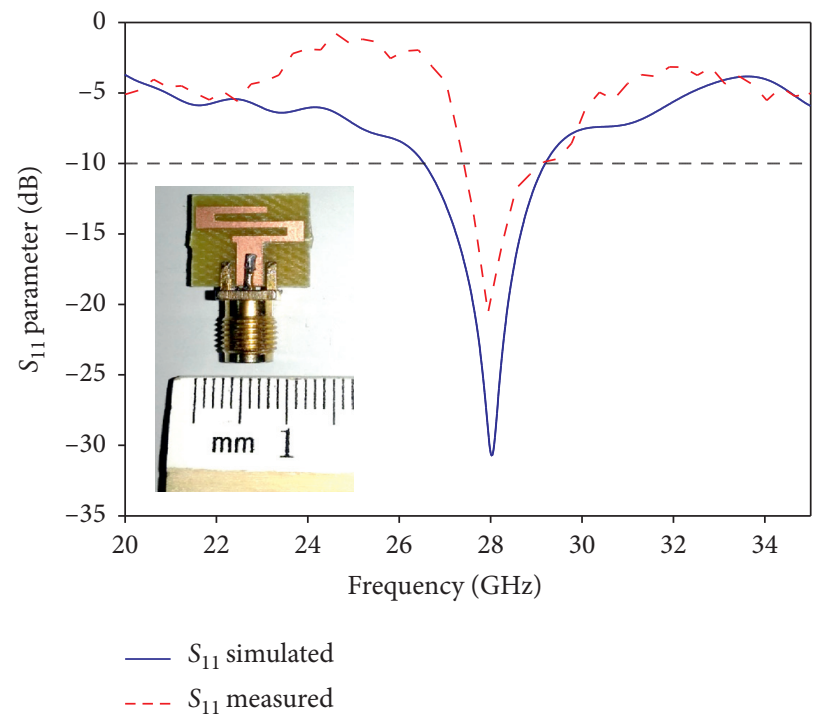

Figure 10: Simulated and measured reflection coefficients of the proposed single antenna.

TABLE 2: Simulated and measured $S 11$ and bandwidth of the single antenna.

\begin{tabular}{lccc}
\hline Single $5 \mathrm{G}$ antenna & Resonance frequency $(\mathrm{GHz})$ & Reflection coefficient $(\mathrm{dB})$ & Bandwidth $(\mathrm{GHz})$ \\
\hline Measured & 27.94 & -20.58 & $27.36-29.39$ \\
Simulated & 28.04 & -30.73 & $26.56-29.3$ \\
\hline
\end{tabular}

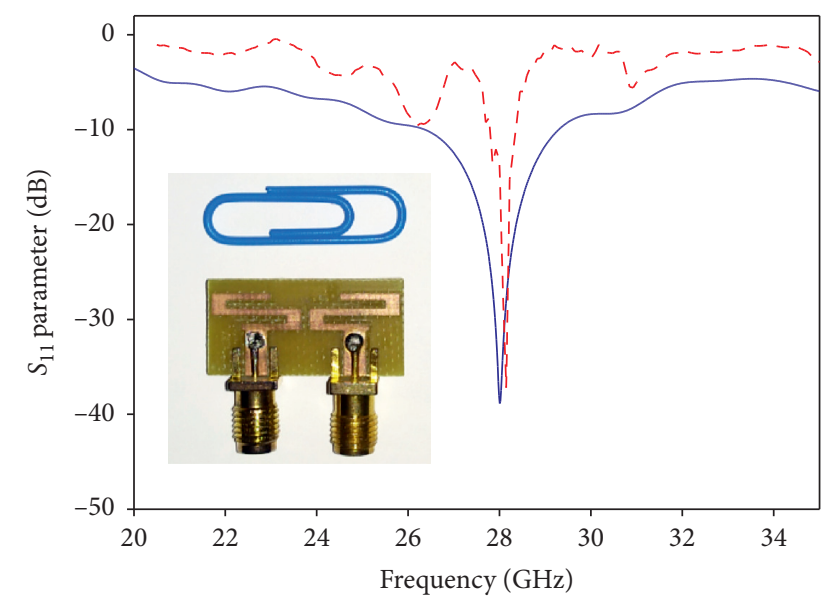

$-S_{11}$ simulated

- - $S_{11}$ measured

FIGURE 11: Simulated and measured reflection coefficients (S11) of the proposed MIMO antenna.

is $41.36 \mathrm{~dB}$ for the experimental results and $36.51 \mathrm{~dB}$ for simulation, meaning that the two antennas are independent of each other. From all these features, we can conclude that the proposed MIMO antenna has a good performance, as indicated in Table 3.

\section{MIMO Antenna Performance Parameters}

For the evaluation of a Multiple Input Multiple Output antenna, it is important to analyze some parameters: the

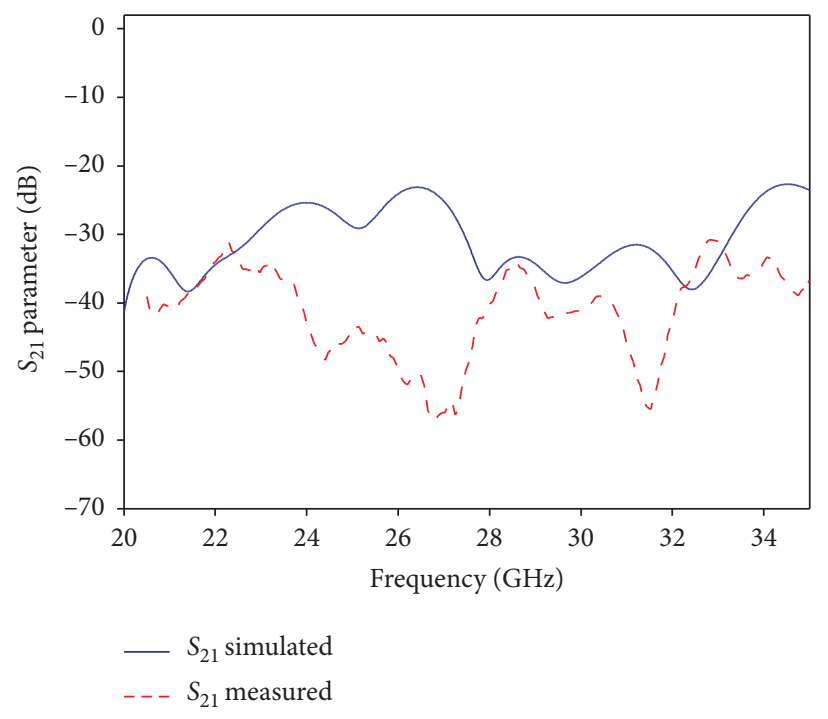

Figure 12: Simulated and measured transmission coefficients (S21) of the proposed MIMO antenna.

envelope correlation coefficient "ECC" which represents the main parameter, the diversity gain " $\mathrm{DG}$ " and total active reflection coefficient "TARC" as well as the efficiency and gain. Therefore, the purpose of this section is to calculate each of these parameters.

5.1. Efficiency and Gain. The simulated realized gain and efficiency of the proposed 5G MIMO antenna are illustrated 
TABLE 3: Simulated and measured $S 11$ and $S 12$ of the 5G MIMO antenna.

\begin{tabular}{lccc}
\hline Proposed 5G MIMO antenna & Fr $(\mathrm{GHz})$ & Reflection coefficient $(\mathrm{dB})$ & Isolation $(\mathrm{dB})$ \\
\hline Measured & 28.12 & -37.17 & -41.36 \\
Simulated & 28.02 & -38.93 & -36.51 \\
\hline
\end{tabular}

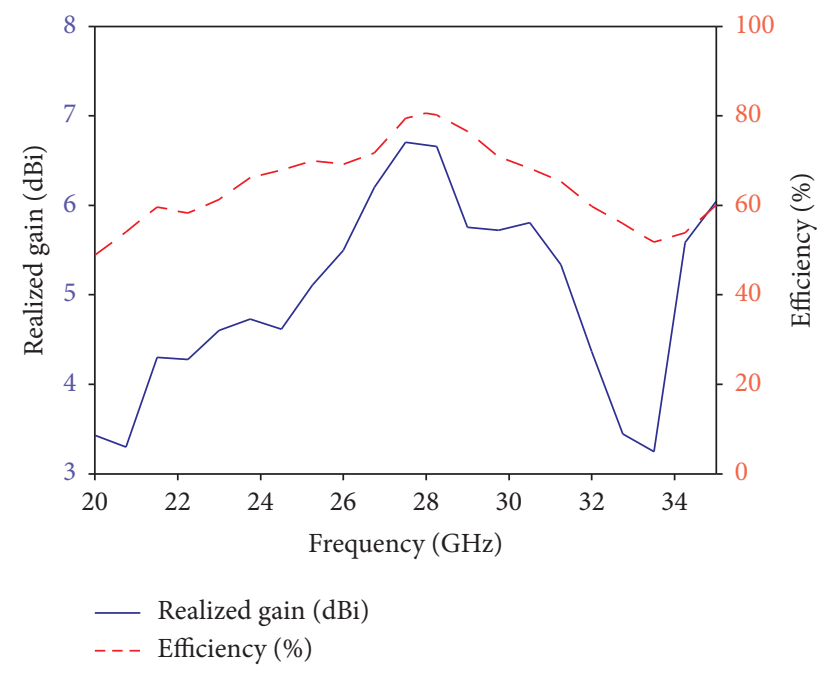

FIGURE 13: Realized gain and total efficiency of the proposed MIMO antenna.

in Figure 13. At the resonance frequency of $28 \mathrm{GHz}$, it is clear that the MIMO antenna offers a gain of $6.68 \mathrm{dBi}$ and the total efficiency is about $80 \%$.

5.2. Envelope Correlation Coefficient and Diversity Gain. The Envelope Correlation Coefficient indicates the degree of independence of the radiation patterns of two antennas. Using the correlation coefficient, we can understand the level of coupling that exists between the antenna ports in the MIMO system. Minimizing the mutual coupling would involve reducing the correlation coefficient between the port pairs.

There are two approaches to calculate the correlation coefficient: the far-field radiation pattern [7] and the $S$ parameters [31]. Its value should be less than 0.5 [32]. The envelope correlation coefficient ECC for two-element antennas is calculated using $S$ parameters by the following equation:

$$
\mathrm{ECC}=\rho_{e}=\frac{\left|S_{11}^{*} S_{12}+S_{21}^{*} S_{22}\right|^{2}}{\left(1-\left(\left|S_{11}\right|^{2}+\left|S_{21}\right|^{2}\right)\right)\left(1-\left(\left|S_{22}\right|^{2}+\left|S_{12}\right|^{2}\right)\right)}
$$

The diversity gain is related to the ECC, and they are linked by the following equation:

$$
\mathrm{DG}=10 \sqrt{1-|\rho|^{2}}
$$

where $|\rho|^{2}=\rho_{e}$

The measured and simulated ECC and DG for the proposed MIMO antenna are shown in Figure 14. As can be seen from this figure, the value of simulated ECC is an ideal value of $1.1510^{-7}$ at $28 \mathrm{GHz}$ frequency, while the corresponding

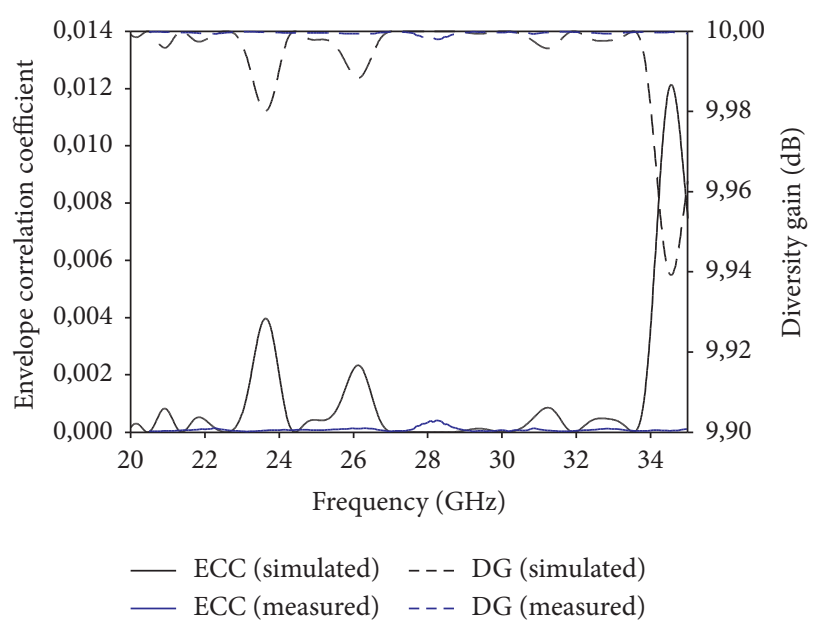

FIgURE 14: ECC and DG of the proposed MIMO antenna.

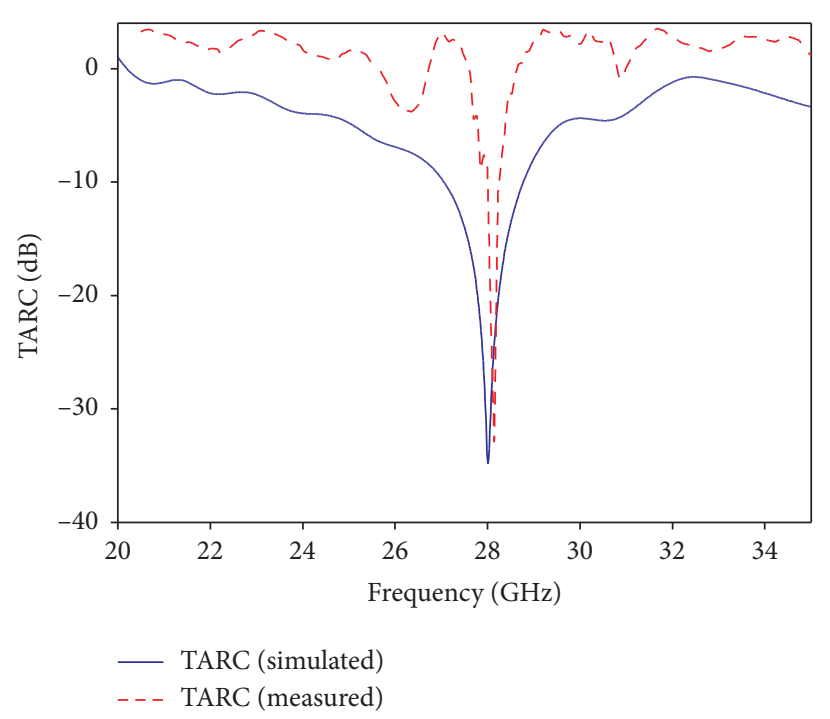

FIgURE 15: TARC of the proposed MIMO antenna.

diversity gain value is around 10, which means that the proposed MIMO antenna has a good performance.

5.3. Total Active Reflection Coefficient. The total active reflection coefficient is the square root of the sum of all reflected powers at the ports, divided by the sum of all incident powers at the ports of an $\mathrm{N}$-port antenna. TARC can be obtained directly from the scattering matrix by the following equation [33]:

$$
\Gamma=\frac{\sqrt{\sum_{i=1}^{N}\left|b_{i}\right|^{2}}}{\sqrt{\sum_{i=1}^{N}\left|a_{i}\right|^{2}}}
$$




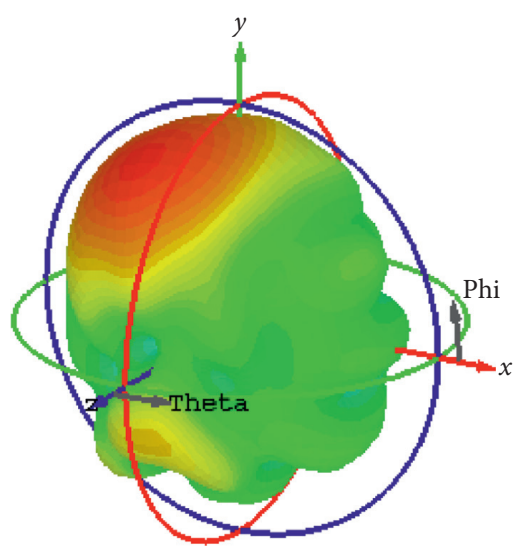

(Port 1)

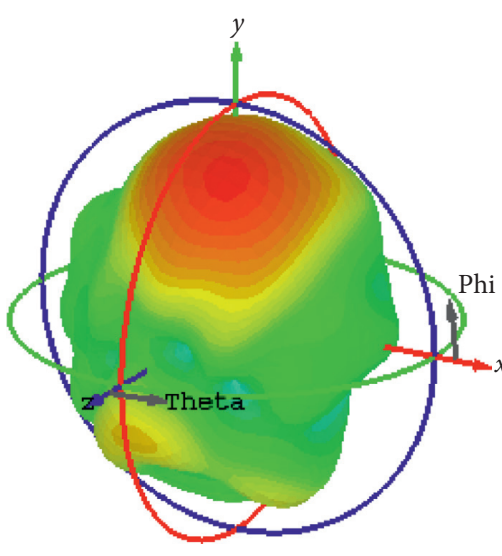

(Port 2)

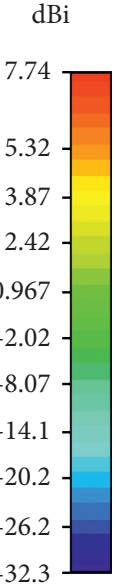

Figure 16: 3D Radiation pattern of the proposed MIMO antenna at $28 \mathrm{GHz}$.

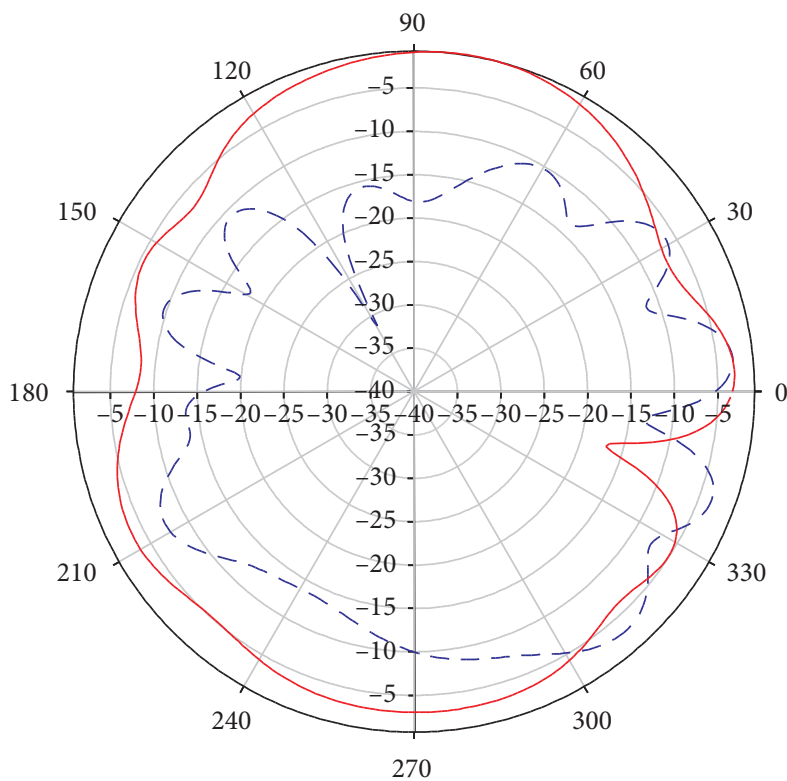

E-Plane

- - Cross-pol

- Co-pol

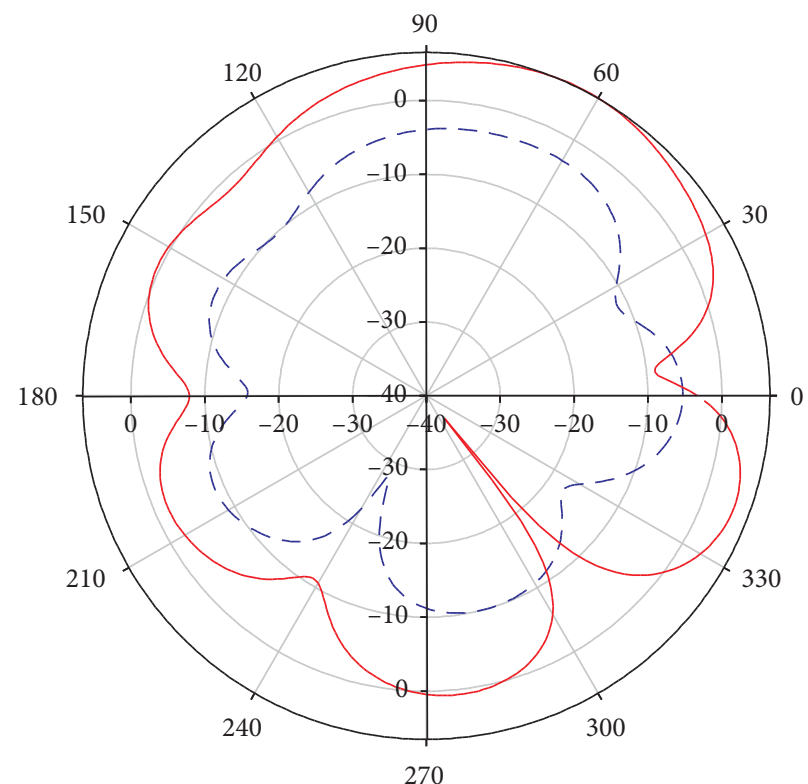

H-Plane

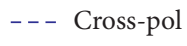

- Co-pol

(a)

(b)

Figure 17: Radiation pattern of the proposed MIMO antenna in E-plane and H-plane at $28 \mathrm{GHz}$.

where $b_{i}$ and $a_{i}$ are the reflected and incident signals, respectively.

After simplification, equation (3) became as follows [34]:

$$
\text { TARC }=\sqrt{\frac{\left|\left(S_{11}+S_{12} e^{j \theta}\right)\right|^{2}+\left|\left(S_{22}+S_{21} e^{j \theta}\right)\right|^{2}}{2}} .
$$

Figure 15 represents the measured and simulated TARC of the proposed MIMO antenna. As can be seen from this figure, it is better than $-10 \mathrm{~dB}$ at the operating band.
5.4. Radiation Pattern. The 3D radiation pattern of the proposed 5G MIMO antenna is reported in Figure 16 for the two antenna ports: port 1 and port 2 at the desired frequency $28 \mathrm{GHz}$. As can be remarked from this figure, the suggested antenna is directional and has a maximum directivity of $7.74 \mathrm{dBi}$.

Furthermore, Figure 17 shows the simulated far-field radiation patterns of the proposed MIMO antenna in E-plane and $\mathrm{H}$-plane copolarization, cross-polarization at $28 \mathrm{GHz}$ when port 1 is excited, and other port are terminated with a $50 \Omega$ load. 
TABle 4: Performance comparisons of the proposed MIMO antenna with recently published works.

\begin{tabular}{|c|c|c|c|c|c|c|c|c|c|}
\hline Ref & Year & Antenna size $\left(\mathrm{mm}^{2}\right)$ & No. of elements & Fr $(\mathrm{GHz})$ & $\mathrm{BW}(\mathrm{GHz})$ & $\mathrm{S} 11(\mathrm{~dB})$ & Isolation $(\mathrm{dB})$ & ECC & $\mathrm{DG}(\mathrm{dB})$ \\
\hline This work & 2020 & $12.8 \times 26=332.8$ & 2 & 28 & 3 & 37.17 & 41.36 & $1.1510^{-7}$ & 10 \\
\hline$[16]$ & 2020 & $30 \times 35=1050$ & 4 & 28 & 4.1 & 30 & 20 & 0.01 & 9.96 \\
\hline [18] & 2019 & $20 \times 20=400$ & 2 & 28 & 0.85 & 25 & 24 & 0.013 & 9.9 \\
\hline [17] & 2019 & $55 \times 110=6050$ & 4 & $\begin{array}{l}28 \\
38\end{array}$ & - & $\begin{array}{l}21.57 \\
24.59\end{array}$ & $\begin{array}{l}28.32 \\
26.27\end{array}$ & $\begin{array}{l}2.4610^{-5} \\
7.6510^{-5}\end{array}$ & NG \\
\hline [19] & 2018 & $31 \times 48=1488$ & 4 & 28 & 5 & - & 21 & $1.510^{-3}$ & NG \\
\hline [20] & 2018 & $12 \times 24=288$ & 2 & 28 & 2.5 & 25 & NG & 0.001 & NG \\
\hline [21] & 2017 & $48 \times 21=1008$ & 2 & 30 & 1 & - & 25 & 0.002 & NG \\
\hline [22] & 2017 & $42 \times 85=3570$ & 2 & 28 & 5 & - & 37.1 & NG & NG \\
\hline
\end{tabular}

NG: not given.

\section{Performance Comparison}

Table 4 displays the performance comparison between the proposed MIMO 5G antenna and recently published articles. This comparison has been made in terms of overall size, the bandwidth, isolation, ECC, and diversity gain.

According to Table 4, our antenna has a compact size compared to other published designs, very high isolation, and an ideal ECC compared to all listed references. Furthermore, the proposed antenna has a simple structure and sufficient bandwidth.

Finally, based on these results and performances, we can say that the suggested antenna is suitable for MIMO system applications and is a good candidate for $5 \mathrm{G}$ applications.

\section{Conclusion}

In this paper, a two-port, multiple-input, multipleoutput antenna with high isolation and low correlation for $5 \mathrm{G}$ applications was presented. This antenna is a symmetrical arrangement of two single antennas having a compact size of $12.8 \times 13 \times 1.6 \mathrm{~mm}^{3}$. Prototype antennas are manufactured and measured. A good agreement is obtained between measurements and simulations. The measured bandwidths of the proposed antennas cover the $28 \mathrm{GHz}$ band $(27.5-28.35 \mathrm{GHz})$ allocated by the Federal Communications Commission for 5G applications. The isolation between the two elements of the MIMO antenna is $41.36 \mathrm{~dB}$ at the resonant frequency. Using the spatial diversity technique, high isolation was achieved without adding any other technique. The envelope correlation coefficient has a value of $1.1510^{-7}$, whereas the diversity gain is around $10 \mathrm{~dB}$, while the TARC is less than $-10 \mathrm{~dB}$ in the operating band. Moreover, the gain and efficiency of the proposed MIMO antenna are also analyzed and are shown to be satisfactory. These results show that the proposed antenna has the main advantages, such as compact size, high isolation, and low ECC when compared to other works. As a consequence, the proposed antenna may be useful for $5 \mathrm{G}$ MIMO applications.

\section{Data Availability}

All data generated during this study are included in this article.

\section{Conflicts of Interest}

The authors declare that they have no conflicts of interest.

\section{Acknowledgments}

This work was carried out with the support of the CNRST within the framework of the Research Excellence Scholarship Program. The authors would like to thank Professor Mohamed TAOUZARI of ENSA, Hassan $1^{\text {st }}$ University, Berrechid, Morocco, for his support with regards to the measure of the proposed antennas.

\section{References}

[1] B. Fady, J. Terhzaz, A. Tribak, F. Riouch, and A. Mediavilla Sanchez, "Novel miniaturized planar low-cost multiband antenna for industry 4.0 communications," Progress In Electromagnetics Research C, vol. 93, pp. 29-38, 2019.

[2] “5G. Vision.", . https://5g-ppp.eu/wp-content/uploads/2015/ 02/5G-Vision-Brochure-v1.pdf, 2020.

[3] “Les enjeux de la 5g," 2017, https://www.arcep.fr/uploads/tx_ gspublication/rapport-enjeux-5G_mars2017.pdf, 2020.

[4] T. S. Rappaport, Y. Xing, G. R. MacCartney, A. F. Molisch, E. Mellios, and J. Zhang, "Overview of millimeter wave communications for fifth-generation (5G) wireless networkswith a focus on propagation models," IEEE Transactions on Antennas and Propagation, vol. 65, no. 12, pp. 6213-6230, 2017.

[5] W. El-Halwagy, R. Mirzavand, J. Melzer, M. Hossain, and P. Mousavi, "Investigation of wideband substrate-integrated vertically-polarized electric dipole antenna and arrays for mm-wave 5G mobile devices," IEEE Access, vol. 6, pp. 2145-2157, 2017.

[6] Q. Cai, Y. Li, X. Zhang, and W. Shen, "Wideband MIMO antenna array covering 3.3-7.1 GHz for $5 \mathrm{G}$ metal-rimmed smartphone applications," IEEE Access, vol. 7, pp. 142070142084, 2019.

[7] Z. Ren and A. Zhao, "Dual-band MIMO antenna with compact self-decoupled antenna pairs for $5 \mathrm{G}$ mobile applications," IEEE Access, vol. 7, pp. 82288-82296, 2019.

[8] M. Abdullah, Y.-L. Ban, K. Kang, M.-Y. Li, and M. Amin, "Eight-element antenna array at 3.5 Ghz for mimo wireless application," Progress In Electromagnetics Research C, vol. 78, pp. 209-216, 2017.

[9] H. Al-Saif, M. Usman, M. T. Chughtai, and J. Nasir, "Compact ultra-wide band MIMO antenna system for lower 5G bands," Wireless Communications and Mobile Computing, vol. 2018, Article ID 2396873, 6 pages, 2018. 
[10] D. EL Hadri, A. Zugari, and A. Zakriti, "The study of a 5G antenna with encoche and defected ground structure (DGS) using the iterative method," in Proccedings of the IEEE, WITS, Fez, Morocco, April 2019.

[11] D. EL Hadri, A. Zugari, and A. Zakriti, "Analysis of a $38 \mathrm{GHz}$ band Antenna for 5G wireless communication using wave concept iterative procedure ( WCIP ) method," in Proceedings of the EAI, ICCWCS, Kénitra, Morocco, April 2019.

[12] N. Ojaroudiparchin, M. Shen, and G. F. Pedersen, "A $28 \mathrm{GHz}$ FR-4 compatible phased array antenna for $5 \mathrm{G}$ mobile phone applications," in Proceedings of the IEEE, ISAP, Hobart, TAS, Australia, December 2015.

[13] A. C. S. Jr, I. F. da Costa, R. A. dos Santos, H. R. D. Filgueiras, and D. H. Spadoti, "Waveguide-based antenna arrays for 5G networks," International Journal of Antennas and Propagation, 2018

[14] M. C. Jose, S. Radha, B. S. Sreeja, and P. Kumar, "Design of 28 $\mathrm{GHz}$ high gain 5G MIMO antenna array system,", in Proceedings of the IEEE Region 10 Annual International Conference, TENCON, pp. 1913-1916, Kochi, India, October 2019.

[15] Y. Rahayu, I. P. Sari, D. I. Ramadhan, and R. Ngah, "High gain 5G MIMO antenna for mobile base station," International Journal of Electrical and Computer Engineering (IJECE), vol. 9, no. 1, pp. 468-476, 2019.

[16] M. Khalid, I. N. Syeda, H. Niamat et al., "4-port MIMO antenna with defected ground structure for $5 \mathrm{G}$ millimeter wave applications," Electronics, vol. 9, no. 1, 2020.

[17] H. M. Marzouk, M. I. Ahmed, and A.-E. H. Shaalan, "Novel dual-band 28/38 GHz MIMO antennas for $5 \mathrm{~g}$ mobile applications," Progress In Electromagnetics Research C, vol. 93, pp. 103-117, 2019.

[18] Y. Zhang, J.-Y. Deng, M.-J. Li, D. Sun, and L.-X. Guo, “A MIMO dielectric resonator antenna with improved isolation for 5G mm-wave applications," IEEE Antennas and Wireless Propagation Letters, vol. 18, no. 4, pp. 747-751, 2019.

[19] Z. Wani, M. P. Abegaonkar, and S. K. Koul, "A 28-GHz antenna for 5G MIMO applications," Progress In Electromagnetics Research Letters, vol. 78, pp. 73-79, 2018.

[20] M. N. Hasan and M. Seo, "Compact omnidirectional $28 \mathrm{GHz}$ $2 \times 2$ MIMO antenna array for 5G communications," in Proceedings of the International Symposium on Antennas and Propagation (ISAP), Busan, Korea, October 2018.

[21] M. S. Sharawi, S. K. Podilchak, M. T. Hussain, and Y. M. M. Antar, "Dielectric resonator based MIMO antenna system enabling millimetre-wave mobile devices," IET Microwaves, Antennas \& Propagation, vol. 11, no. 2, pp. 287-293, 2017.

[22] S. Gupta, Z. Briqech, A. R. Sebak, and T. Ahmed Denidni, "Mutual-coupling reduction using metasurface corrugations for $28 \mathrm{GHz}$ MIMO applications," IEEE Antennas and Wireless Propagation Letters, vol. 16, pp. 2763-2766, 2017.

[23] N. K. Mallat, M. Ishtiaq, A. Ur Rehman, and A. Iqbal, "Millimeter-wave in the face of $5 \mathrm{G}$ communication potential applications," IETE Journal of Research, pp. 1-9, 2020.

[24] T. S. Rappaport, R. Shu Sun, R. Mayzus et al., "Millimeter wave mobile communications for $5 \mathrm{G}$ cellular: it will work!" IEEE Access, vol. 1, pp. 335-349, 2013.

[25] C. K. Agubor, I. Akwukwuegbu, M. Olubiwe et al., "A comprehensive review on the feasibility and challenges of millimeter wave in emerging 5G mobile communication," Advances in Science, Technology and Engineering Systems Journal, vol. 4, no. 3, pp. 138-144, 2019.

[26] M. Xiao, S. Mumtaz, Y. Huang et al., "Millimeter wave communications for future mobile networks," IEEE Journal on Selected Areas in Communications, vol. 35, no. 9, pp. 1909-1935, 2017.

[27] H. Mahmud, "Cellular mobile technologies ( $1 \mathrm{G}$ to 5G ) and massive MIMO," International Journal of Science and Research, vol. 8, no. 7, pp. 929-937, 2019.

[28] M. a. J. Al-Hasan, T. A. Denidni, and A. R. Sebak, "Millimeterwave compact EBG structure for mutual coupling reduction applications," IEEE Transactions on Antennas and Propagation, vol. 63, no. 2, pp. 823-828, 2015.

[29] M. Farahani, J. Pourahmadazar, M. Akbari, M. Nedil, A. R. Sebak, and T. A. Denidni, "Mutual coupling reduction in millimeter-wave MIMO antenna array using a metamaterial polarization-rotator Wall," IEEE Antennas and Wireless Propagation Letters, vol. 16, pp. 2324-2327, 2017.

[30] X. Shi, M. Zhang, S. Xu, D. Liu, H. Wen, and J. Wang, "Dualband 8-element MIMO antenna with short neutral line for $5 \mathrm{G}$ mobile handset," in Proceedings of the 11th European Conference on Antennas and Propagation, EUCAP, Paris, France, March 2017.

[31] Z. Xu, Q. Zhang, and L. Guo, "A compact 5G decoupling MIMO antenna based on split-ring resonators," International Journal of Antennas and Propagation, vol. 2019, Article ID 3782528, 10 pages, 2019.

[32] Y.-L. Ban, C. Li, C.-Y.-D. Sim, G. Wu, and K.-L. Wong, “4G/ 5G multiple antennas for future multi-mode smartphone applications," IEEE Access, vol. 4, pp. 2981-2988, 2016.

[33] F. Wang, Z. Duan, X. Wang, Q. Zhou, and Y. Gong, "High isolation millimeter-wave wideband MIMO antenna for $5 \mathrm{G}$ communication," International Journal of Antennas and Propagation, vol. 2019, Article ID 4283010, 12 pages, 2019.

[34] S. H. Chae, S.-k. Oh, and S.-O. Park, "Analysis of mutual coupling, correlations, and TARC in WiBro MIMO array antenna," IEEE Antennas and Wireless Propagation Letters, vol. 6, pp. 122-125, 2007. 